See Article page 1.

\section{Commentary: There is nothing like looking, if you want to find something}

\author{
Michele Di Mauro, MD, PhD, MSc, ${ }^{\text {a }}$ \\ Giorgia Bonalumi, MD, ${ }^{\mathrm{b}}$ Antonio M. Calafiore, MD, \\ and Alessandro Parolari, $\mathrm{MD}^{\mathrm{d}}$
}

Aorta-to-right atrial fistula is a rare but very serious complication of infective endocarditis and predicts a greater mortality $^{1}$ or a congenital condition also known as aorta-right atrial tunnel. ${ }^{2}$ Aorta-to-right atrial fistulas as a complication of type A aortic dissection have been described as anecdotal cases since $1973 .^{3-6}$ All these cases, as well as the case reported by Kitada and colleagues, ${ }^{7}$ demonstrate the close anatomic relationship between the aortic root and the right atrium. Anatomically, the right atrium adjoins the aorta in the area between the noncoronary and right coronary cusps. In $70 \%$ of cases, the aorta-right atrial fistula originates in the noncoronary cusp. ${ }^{4}$

The peculiarity of this case lies in the fact that from the inside of the aorta, the origin of the fistula was not available because the lesion was at the level of the adventitia and therefore it was the false and not the true lumen to communicate with the right atrium. This led surgeons to close the fistula using horizontal mattress sutures from the right atrium to the aorta, through around the fistula, reinforcing with 2 patches, Dacron on the right atrial side and autologous pericardium inside the aorta. The take-home message of this case report can be summarized

\footnotetext{
From the ${ }^{\mathrm{a}}$ Department of Heart Disease, SS Annunziata Hospital, Chieti; ${ }^{\mathrm{b}}$ Department of Cardiac Surgery, Centro Cardiologico Monzino, Milan; ${ }^{\mathrm{c}}$ Department of Cardiac Surgery, Pope John Paul II Foundation, Campobasso; and ${ }^{\mathrm{d}}$ UOC Cardiac Surgery and Translational Research, IRCCS San Donato and University of Milan, San Donato Milanese, Italy.

Disclosures: Authors have nothing to disclose with regard to commercial support.

Received for publication Nov 25, 2019; revisions received Nov 25, 2019; accepted for publication Nov 29, 2019; available ahead of print Feb 13, 2020.

Address for reprints: Michele Di Mauro, MD, PhD, MSc Biostat, Heart Disease Department, SS Annunziata Hospital, Via dei Vestini, 66100, Chieti, Italy (E-mail: mdimauro1973@gmail.com).

JTCVS Techniques 2020;1:5

2666-2507

Copyright (c) 2020 The Author(s). Published by Elsevier Inc. on behalf of The American Association for Thoracic Surgery. This is an open access article under the CC BY-NC-ND license (http://creativecommons.org/licenses/by-nc-nd/4.0/).

https://doi.org/10.1016/j.xjtc.2019.11.015
}

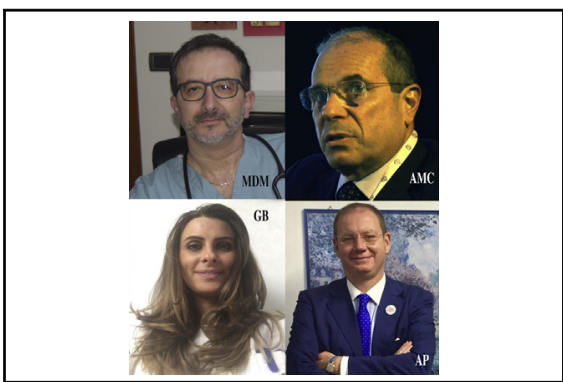

Michele Di Mauro, MD, PhD, MSc (MDM), Giorgia Bonalumi, MD (GB), Antonio M. Calafiore, MD (AMC), and Alessandro Parolari, MD (AP)

\section{CENTRAL MESSAGE \\ Aorta-to-right atrial fistula is a rare but very serious complica- tion of aortic dissection. We need to search for it before starting the operation.}

with a quote by J.R.R. Tolkien: "There is nothing like looking, if you want to find something. You certainly usually find something, if you look, but it is not always quite the something you were after."

\section{References}

1. Chen MY, Zhong DD, Ying ZQ. Aorta-to-right atrium fistula, an unusual complication of endocarditis. J Zhejiang Univ Sci B. 2009;10:230-2.

2. Gajjar T, Voleti C, Matta R, Iyer R, Dash PK, Desai N. Aorta-right atrial tunnel clinical presentation, diagnostic criteria, and surgical options. J Thorac Cardiovasc Surg. 2005;130:1287-92.

3. Page AJ, Yacoub MH, Sutton GC. Aorto-right atrial fistula. A rare complication of aortic dissection. Br Heart J. 1973;35:1338-40.

4. Frank MW, Stout MJ. Acute aortic dissection with an aorta-right atrium fistula. Tex Heart Inst J. 2003;30:335-6.

5. Scalia D, Rizzoli G, Scomparin MA, Testolin L, Isabella GB, Casarotto D Aorto-right atrial fistula: a rare complication of aortic dissection type A. A report of two cases. J Cardiovasc Surg (Torino). 1997;38:619-22.

6. Matsuhisa H, Obo H, Nakagiri K, Mukohara N, Shida T. Aorto-right atrial fistula caused by type A aortic dissection. Ann Thorac Surg. 2004;78:2173-5.

7. Kitada Y, Arakawa M, Miyagawa A, Okamura H. Acute type A aortic dissection complicated with an aorto-right atrial fistula. J Thorac Cardiovasc Surg Tech 2020;1:1-3. 